\title{
18F-FDG PET/CT with unusual bone and CNS metastases from testicular seminoma
}

Francisco Javier García Gómez 1, Irene Acevedo Báñez 1, Roberto Lasso Vega González 2, Pedro Jiménez-Granero ${ }^{1}$, Isabel Borrego Dorado ${ }^{1}$

${ }^{1}$ Department of Nuclear Medicine, Virgen del Rocio Univesitary Hospital, Seville, Spain and ${ }^{2}$ Department of Medical Oncology. Virgen del Rocio Universitary Hospital. Seville, Spain

A 31 year old male with a previous history of testicular seminoma with complete reponse after orchiectomy and three cycles of BEP scheme, was referred for $18 \mathrm{~F}-\mathrm{FDG}$ PET/CT with a standard procedure for progressive decline consistent in spinal pain, gait difficulty and Charcot's neurologic triad (scanning speech, intention tremor and nystagmus) initiated eight month after third course of chemotherapy. Dorsal spine MRI revealed a space-occupying lesion at left T6 lamina. Histology examination confirmed a seminoma metastatic to spine.
A wholebody and cerebral 18F-FDG PET/CT scan was performed 60 minutes after intravenous injection of $370 \mathrm{MBq}$ of 18F-FDG. PET/CT scan demonstrated an augmentation of soft tissue due laminectomy with increased uptake of radiotracer and a Standardized Uptake Value (SUV) maximum of 4.84 (Figure-1, Panel a), so persistence of tumour tissue cannot be excluded. Furthermore, two focal hypermetabolic areas in CNS were revealed. First, located in the spinal cord at C4-C5 vertebral levels

Figure 1 - Wholebody and cerebral 18F-FDG PET/CT scan after i.v. administration of 370 MBq of 18F-FDG. Panel a) Axial images that revealed an augmentation of soft tissue due left T6 laminectomy with increased uptake of radiotracer and SUV maximum of 4.84 that cannot allow to excluded the persistence of tumour tissue. Panel b) Sagital images showed a spinal cord metastasis with increased uptake of radiotracer at C4-C5 vertebral levels with a SUV maximum of 7.49. Panel c) Cerebral scan revealed a hypermetabolic mass in cerebellum, with high uptake of 18F-FDG (SUV maximum of 11), corresponding with $3.9 \mathrm{~cm}$ mass in vermix observed at post-hoc MRI scan.

A
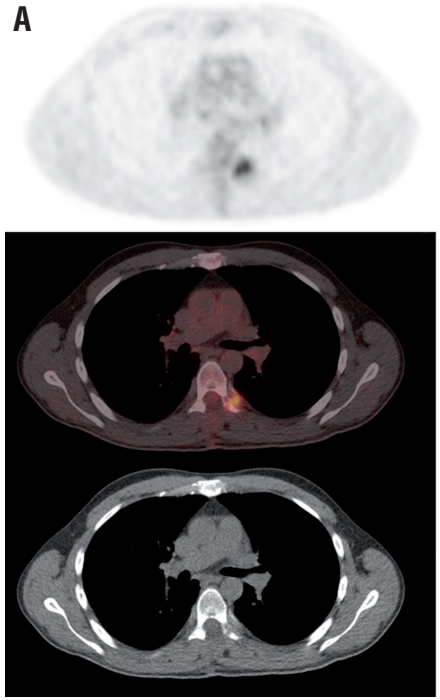

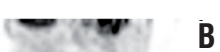

了

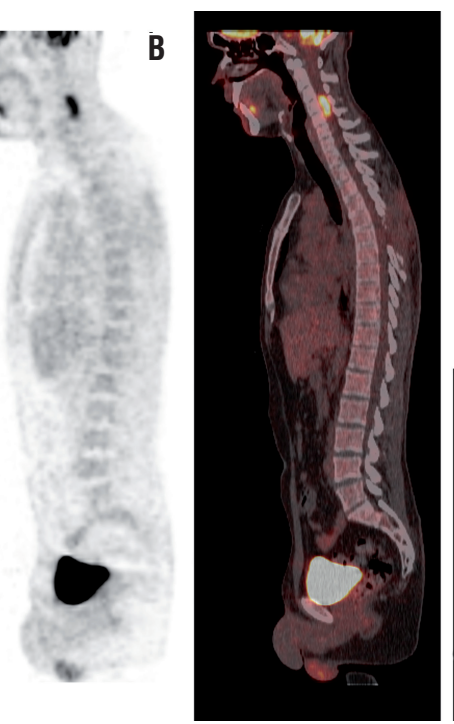

C
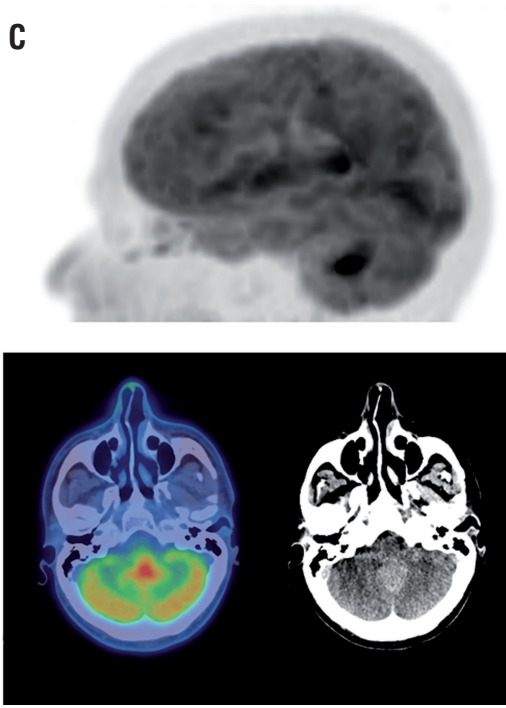
with a SUV maximum of 7.49 (Figure-1, Panel b) and second, in the cerebellum with a SUV maximum of 11 (Figure-1, Panel c), corresponding with $3.9 \mathrm{~cm}$ mass in vermix observed at post-hoc MRI scan.

This is an unusual intra-extracranial metastatic tumor merits active treatment.

Most relapses of seminoma occur within the first 3 years after orchiectomy. Bone and CNS metastases involvement are an extremely rare event. A report of 2,550 patients revealed bone metastases only in 3 patients with seminoma $(0.12 \%)(1)$. Moreover, CNS occurred only once in a series of 142 patients (0.7\%) (2). Higher uptake in seminomas than in nonseminomas testicular carcinomas (3) makes 18F-FDG PET/CT a powerful tool in evaluating postchemotherapy seminoma relapses.

\section{REFERENCES}

1. Jamal-Hanjani M, Karpathakis A, Kwan A, Mazhar D, Ansell W, Shamash J, et al. Bone metastases in germ cell tumours: lessons learnt from a large retrospective study. BJU Int. 2013;112:176-81.

2. Mencel PJ, Motzer RJ, Mazumdar M, Vlamis V, Bajorin DF, Bosl GJ. Advanced seminoma: treatment results, survival, and prognostic factors in 142 patients. J Clin Oncol. 1994;12:120-6.

3. Cremerius U, Effert PJ, Adam G, Sabri 0, Zimmy M, Wagenknecht $G$, et al. FDG PET for detection and therapy control of metastatic germ cell tumor. J Nucl Med. 1998;39:815-22.

ARTICLE INFO

Int Braz J Urol. 2015; 41: 393-4

Submitted for publication: July 27,2014

Accepted after revision: December 10, 2014 